03

\title{
Скорость электрического ветра и КПД преобразования электрической энергии
}

\author{
(c) Н.М. Верещагин, В.В. Васильев
}

Рязанский государственный радиотехнический университет, 390005 Рязань, Россия

e-mail: nmver@yandex.ru

(Поступило в Редакцию 14 марта 2017 г.)

Представлены результаты теоретических и экспериментальных исследований скорости электрического ветра и коэффициента полезного действия. Эксперименты проводились в воздухе при атмосферном давлении на электродной системе „плоский многоострийный электрод-две параллельные трубки“.

DOI: 10.21883/JTF.2018.03.45585.2250

\section{Введение}

Эффект электрического ветра известен давно и широко используется в электротехнологиях $[1,2]$. В последние годы область применения электрического ветра непрерывно расширяется $[3,4]$. Скорость электрического ветра сильно зависит от геометрии электродной системы $[5,6]$. Экспериментальные исследования и компьютерное моделирование показали, что скорость электрического ветра максимальна напротив острия и убывает к периферии. Максимальная ее величина лежит в диапазоне $1-5 \mathrm{~m} / \mathrm{s}$ в зависимости от конструкции электродной системы [3-5]. В многокаскадных конструкциях электродных систем получают направленный поток воздуха со скоростью более $5 \mathrm{~m} / \mathrm{s}$ [7,8].

Известно, что скорость электрического ветра пропорциональна корню квадратному из плотности тока [2], и обратно пропорциональна корню квадратному из подвижности ионов [5].

Представляет интерес исследование путей увеличения скорости электрического ветра и определение коэффициента полезного действия преобразования электрической энергии в кинетическую энергию воздушного потока в коронном разряде.

\section{Теоретическая часть}

Будем рассматривать униполярный коронный разряд, во внешней области которого ионы движутся от коронирующего электрода, создавая плотность электрического тока $j=e n V_{i}$, где $n-$ концентрация ионов, $V_{i}$ - скорость ионов. Энергия, затрачиваемая полем на перемещение заряда от одного электрода до второго, равна произведению заряда $q$, находящегося в объеме, на напряжение $U$, приложенное к электродам $W=q U$. Будем считать, что коронный разряд занимает объем в виде конуса с вершиной на острие коронирующего электрода. Тогда суммарный заряд ионов, находящийся в конусе, можно определить следующим выражением $q=j L S /\left(3 V_{i}\right)$, где $S$ - площадь основания конуса, $L-$ межэлектродное расстояние. С учетом того, что скорость ионов пропорциональна напряженности электрического поля $V_{i}=\mu U / L$, где $\mu-$ подвижность ионов, a $U / L-$ средняя напряженность электрического поля, получим: $q=j L^{2} S /(3 \mu U)$. Отсюда энергия, затрачиваемая полем, по перемещению заряда на расстояние $L$ будет равна $W=q U=j L^{2} S /(3 \mu)$. Будем считать, что вся эта энергия при соударениях ионов передается молекулам воздуха, заключенным в цилиндре длиной $L$ с площадью основания $S$. Масса воздуха, заключенного в этом объеме, определим по формуле $m=\rho L S$, где $\rho$ - плотность воздуха. В результате взаимодействия ионов с молекулами воздуха последние разгонятся до скорости $V$, приобретая энергию $m V^{2} / 2$. Приравняв энергию, затрачиваемую электрическим полем, к кинетической энергии воздушного потока, получим формулу для расчета скорости воздуха

$$
V=\sqrt{\frac{2 j L}{3 \mu \rho}} .
$$

Такой же результат получается при расчете скорости ветра $V$ из условия равенства давлению заряда $P_{1}=q E / S$ на поверхность площадью $S$, давлению ветра $P_{2}=\rho V^{2} / 2$ на площадь той же величины. Приравняв эти выражения $P_{1}=P_{2}$ и преобразовав, получим ту же формулу для скорости:

$$
V^{2}=\frac{2 q E}{\rho S}=\frac{2 L I E}{\rho S 3 V_{i}}=\frac{2 j L}{3 \mu \rho} .
$$

Зная скорость газа $V$ и затрачиваемую мощность $P=U I$, где $I-$ сила тока, можно рассчитать коэффициент полезного действия преобразования электрической энергии в кинетическую энергию газового потока:

$$
\eta=\frac{\bar{m} V^{2}}{2 U I}
$$

где $\bar{m}=\rho S V$ - массовый расход воздуха. После подстановки скорости воздуха получим:

$$
\eta=V /\left(3 V_{i}\right)
$$




\section{Экспериментальная часть}

Экспериментальные исследования проводились при отрицательном коронном разряде на установке, приведенной на рис. 1.

Экспериментальная установка состоит из электродной системы, содержащей коронирующий 1 и некоронирующие электроды 2, которые подключены к высоковольтному источнику питания $U_{\text {in. }}$. Напряжение измерялось киловольтметром С90, а ток - микроамперметром М265М. Коронирующий электрод изготовлен из пластины нержавеющей стали, одна сторона которой имеет зубья треугольной формы (всего 22 зуба). Вершины зубьев задают фиксированные точки зажигания разряда. Некоронирующие электроды выполнены в виде трубок диаметром $6 \mathrm{~mm}$ и расположены параллельно между собой на расстоянии $H=12 \mathrm{~mm}$. Коронирующий электрод располагался симметрично на расстоянии $L$ от краев трубок некоронирующего электрода. В экспериментах межэлектродное расстояние $L$ изменялось в диапазоне 6.5-25 mm, а расстояние $H$ не менялось.

На коронирующий электрод подавалось высокое напряжение отрицательной полярности, некоронирующие электроды находились под нулевым потенциалом.

На рис. 2 приведены экспериментальные зависимости скорости электрического ветра от корня квадратного
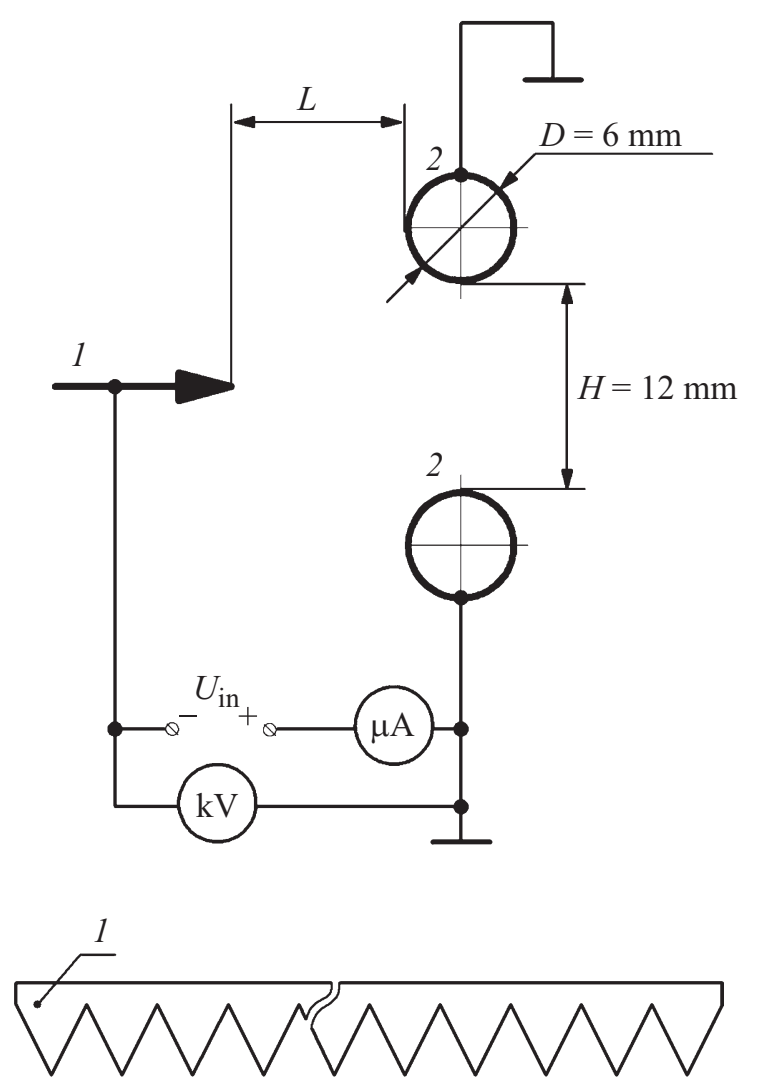

Рис. 1. Структурная схема конструкции электродной системы и форма коронирующего электрода $(1-$ коронирующий электрод, 2 - некоронирующий электрод).

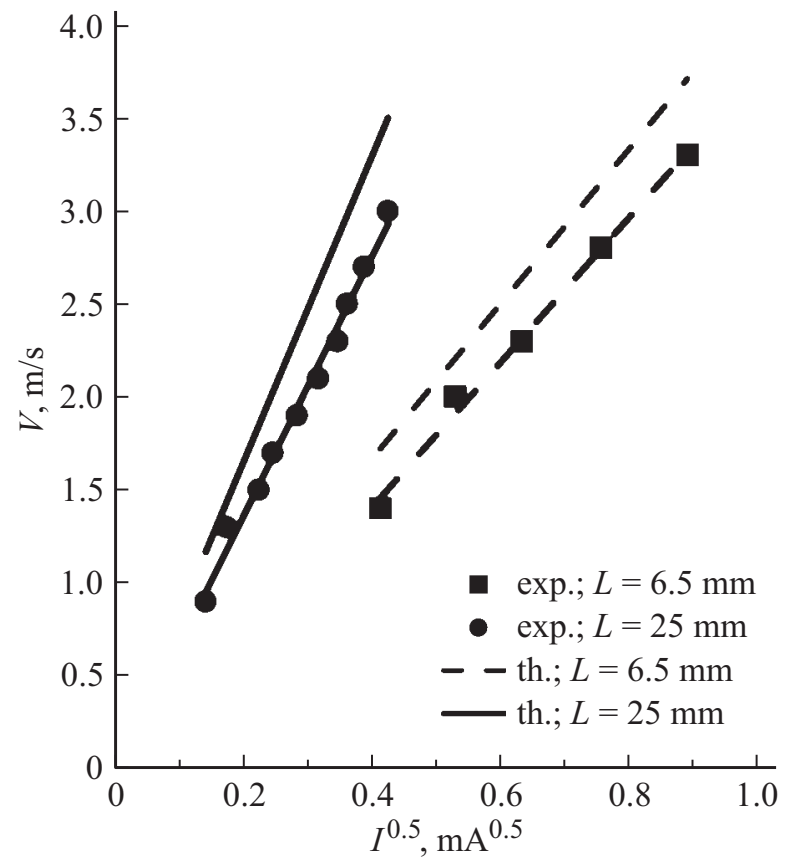

Рис. 2. Зависимость скорости электрического ветра от корня квадратного из тока для различных межэлектродных расстояний.

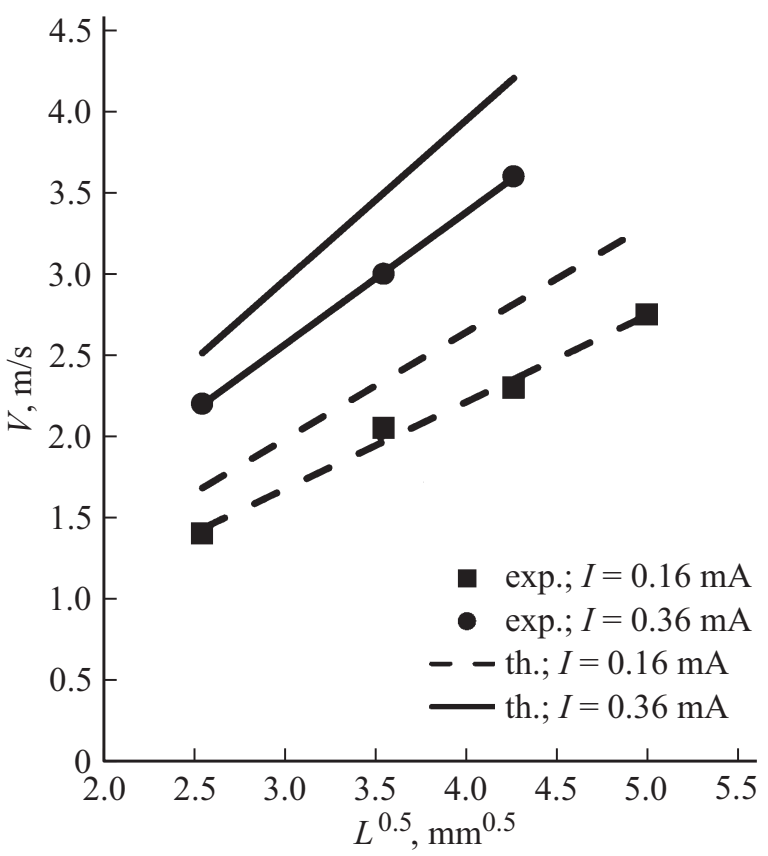

Рис. 3. Зависимость скорости ветра от корня квадратного из межэлектродного расстояния для различных токов.

из тока для различных расстояний между электродами в сравнении с теоретическими зависимостями, рассчитанными по формуле (1). В расчетах принималось: $\rho=1.2 \mathrm{~kg} / \mathrm{m}^{3}, \mu=2 \cdot 10^{-4} \mathrm{~m}^{2} / \mathrm{V} \cdot \mathrm{s}$.

Измерение скорости воздушного потока производилось крыльчатым анемометром Windmate 100. Анемо- 
Зависимость КПД от тока коронного разряда

\begin{tabular}{c|c|c|c|l|c}
\hline \multicolumn{6}{c}{$L=12.5 \mathrm{~mm}$} \\
\hline$U, \mathrm{kV}$ & $I, \mu \mathrm{A}$ & $P, \mathrm{~W}$ & $V, \mathrm{~m} / \mathrm{s}$ & $\eta, \%$ & $\eta_{\text {theor }} \%$ \\
\hline 10 & 0.03 & 0.3 & 0.9 & 0.15 & 0.21 \\
14 & 0.2 & 2.8 & 2.1 & 0.2 & 0.39 \\
16 & 0.32 & 5.12 & 2.9 & 0.29 & 0.43 \\
17 & 0.38 & 6.46 & 3.3 & 0.34 & 0.45
\end{tabular}

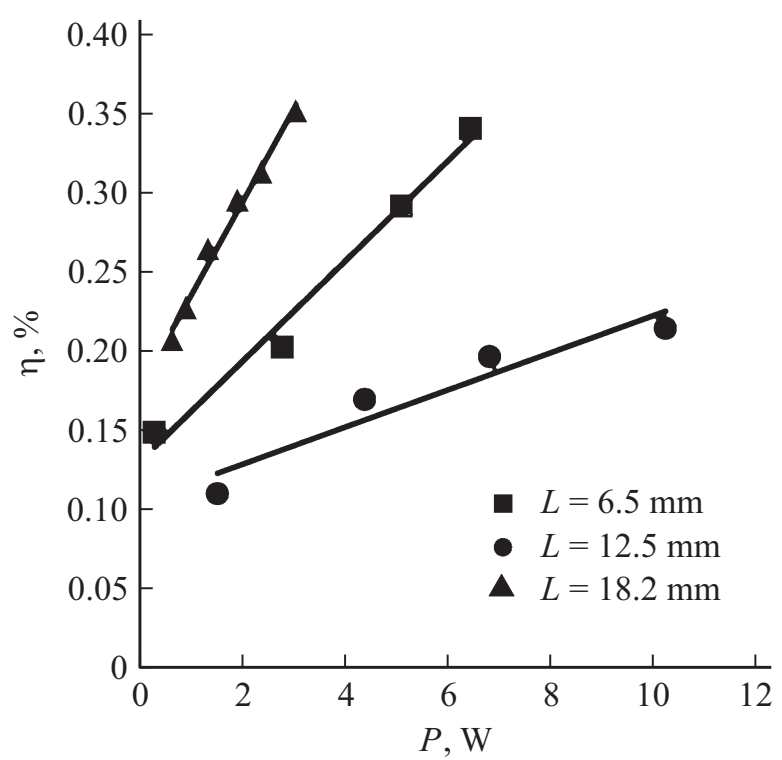

Рис. 4. Зависимость КПД от мощности для различных межэлектродных расстояний.

метр устанавливался на выходе электродной системы на расстоянии $30 \mathrm{~mm}$ от некоронирующих электродов. Погрешность измерений составляет $\pm 3 \%$. Таким образом, происходило измерение средней скорости воздушного потока.

На рис. 3 показаны зависимость скорости электрического ветра от межэлектродного расстояния для разных токов и теоретические зависимости, построенные по формуле (1).

Из зависимостей рис. 2 и 3 видно, что скорость ветра зависит не только от тока, но и от межэлектродного расстояния. Теоретические зависимости достаточно точно согласуются с экспериментальными.

В расчетах средней скорости ионов принималась средняя напряженность электрического поля. Результаты расчета приведены в таблице. Из нее видно, что экспериментальные и рассчитанные по формуле (2) значения КПД близки по величине.

КПД возрастает с увеличением напряжения и межэлектродного расстояния (таблица, рис. 4). В зависимостях (рис. 4) вводимая в разряд мощность была ограничена либо максимальным напряжением источника питания на уровне $17 \mathrm{kV}$ при большом межэлектродном расстоянии, либо пробоем промежутка при малом межэлектродном расстоянии.

В соответствии с формулой (2) КПД возрастает пропорционально отношению скорости ветра к скорости ионов. Из таблицы видно, что скорость ветра растет быстрее напряжения приложенного к электродам, т.е. быстрее скорости ионов, что и является причиной увеличения КПД. Возрастание КПД от межэлектродного расстояния также вызвано увеличением рабочего напряжения. В исследуемой конструкции электродной системы КПД возрастал пропорционально напряжению, прикладываемому к электродам.

\section{Заключение}

По результатам проведенных исследований можно сделать выводы:

1) скорость электрического ветра зависит не только от плотности тока и подвижности ионов, но и от расстояния между электродами и от удельной плотности воздуха. Увеличение межэлектродного расстояния приводит к увеличению скорости ветра, а увеличение плотности воздуха уменьшает скорость;

2) КПД определяется отношением скорости ветра к скорости ионов, возрастает с увеличением мощности, вводимой в разряд, и межэлектродного расстояния. КПД в исследуемой электродной системе не превышал $0.35 \%$.

\section{Список литературы}

[1] Капцов Н.А. Коронный разряд и его применение в электрофильтрах. М.-Л.: Гос. изд-во техн.-теор. лит., 1947. 226 с.

[2] Верещагин И.П. Коронный разряд в электронно-ионной технологии // М.: Энергоатомиздат, 1985. 160 с.

[3] Ребров И.Е., Хомич В.Ю., Ямщииков В.А. // ЖТФ. 2016. T. 86. № 8. C. 10-14.

[4] Ашихмин И.А., Самусенко А.В. // ЖТФ. 2015. Т. 85. № 11. C. $65-72$.

[5] Козлов Б.А., Соловьев В.И. // ЖТФ. 2007. Т. 77. № 7. С. 70 76.

[6] Козлов Б.А., Соловьев В.И. // ЖТФ. 2006. Т. 76. № 7. С. 1-7.

[7] Верещагин Н.М., Васильев В.В., Королев А.Е., Шемарин К.В. // Вестник Рязанского гос. радиотехнического унта. 2014. № 48. C. 149-152.

[8] Верещагин Н.М., Королев А.Е., Васильев В.В., Шемарин К.В. // Вестник Рязанского гос. радиотехнического унта. 2013. № 4-3 (46). С. 64-67. 